\title{
A IMPORTÂNCIA DE ENFERMEIROS EM PESQUISA NA ÁREA DE SAÚDE - UM ENFOQUE HOLÍSTICO
}

É amplamente conhecida a necessidade de membros profissionais de todas as áreas de saúde, incluindo enfermeiros, para entender e aplicar pesquisa no exercício de sua própria profissão. Além disso, a necessidade de encorajar e apoiar enfermeiros a desenvolver a pesquisa e contribuir significativamente para nossa compreensão em assuntos relacionados à saúde; tem sido enfatizado por associações como o Conselho Internacional de Enfermagem (ICN 2007)*. Entretanto, doença e saúde são multifatoriais e frequentemente complexos por natureza; problemas estão raramente confinados a uma disciplina ou profissão em particular. Portanto, pesquisadores precisam adotar uma ampla perspectiva que considere uma vasta variedade de fatores pessoais, biológicos, psicológicos e sociais que possam contribuir a problemas de saúde. Desta forma, uma crescente conscientização dos benefícios de associar várias disciplinas para enfrentar problemas de saúde complexos tem levado a um encorajamento e uso de uma abordagem progressivamente holística, interdisciplinar em pesquisa em saúde.

Uma equipe multiprofissional eficaz vale mais do que a soma das partes individuais; combina uma 'network' robusta de pesquisadores acadêmicos, cientistas eclínicos que possuem uma gama coordenada de habilidades, expertise e experiência. Realizar pesquisa interdisciplinar pode ser desafiador, e motiva indivíduos a aumentar os próprios limites profissionais, colabora disciplinas transversalmente e então, aproxima uma quantidade integral e única de pontos de vista e potencialidades para enfrentar problemas complexos de saúde. Enfermeiros são uma parte fundamental da mão-de-obra na área de saúde e deveriam ser uma peça chave na contribuição para a pesquisa interdisciplinar em saúde.

Inúmeras iniciativas têm sido implementadas ao longo da última década no Reino Unido para promover a importância da alta qualidade em pesquisa clínica dentro do Sistema Nacional de Saúde. Como resultado, tem havido um aumento substancial no número de enfermeiros empregados na área de pesquisa clínica. Enfermeiros pesquisadores clínicos são membros pivôs de uma equipe de pesquisa multidisciplinar; eles possuem uma grande variedade de competências 'chave' como a habilidade de trabalhar de uma forma autônoma; executar tarefas práticas com grande habilidade; comunicar efetivamente, com os membros da equipe e participantes do estudo e seus familiares; preencher a documentação do estudo precisamente e aderir a legislação e orientações da pesquisa. Entretanto, essencialmente o papel é de apoio, tornando possível a pesquisa de outros (frequentemente de outras profissões de saúde, não de enfermagem), como distinto de um verdadeiro pesquisador multidisciplinar. Contudo, pesquisa clínica pode prover uma fundação ideal em que enfermeiros podem desenvolver as suas próprias ideias em pesquisa e progredir em sua carreira em pesquisa.

A minha própria carreira começou como uma enfermeira em pesquisa clínica, no departamento de asma e alergia. Interessada em seguir os meus próprios questionamentos em pesquisa, inicialmente fiz um doutorado investigando os efeitos da poluição do ar, nos sintomas de asma em crianças em idade escolar. Durante todo o meu estudo de pós-graduação, eu recebi supervisão e apoio consideráveis de diversas disciplinas, incluindo epidemiologia, enfermagem, medicina, física, psicologia, estatística, geografia e educação. Isto tornou-se uma alavanca para uma carreira acadêmica como parte de uma equipe interdisciplinar. Um dos desafios em pesquisa no qual estou atualmente envolvida, diz respeito em como devemos adaptar melhor as necessidades e desafios do envelhecimento da população global. A equipe compreende uma variedade de 'experts' de áreas incluindo engenharia biomédica, epidemiologia, saúde econômica, enfermagem, medicina, nutrição, terapia ocupacional, psicologia e estatística.

${ }^{1}$ Enfermeira. Pós doutora em Pesquisa. Universidade de Southampton. Southampton - Inglaterra.

*International Council of Nurses (2007) ICN Policy on Nursing Research www.icn.ch/images/stories/documents/publications/ position_statements/BO5_Nsg_Research.pdf 
Recentemente, esquemas estruturados de treinamento acadêmico têm sido estabelecidos, primordialmente na configuração clínica, para prover oportunidades para enfermeiros no Reino Unido, a seguir uma carreira em pesquisa. Esforços em dar enfoque para uma melhor conscientização entre graduandos de Enfermagem, sobre as grandes possibilidades numa carreira em pesquisa na área de saúde. Entretanto, estas iniciativas promissoras precisam ser construídas para consolidar a capacidade de pesquisa em enfermagem no futuro. É vital desenvolver estratégias para alimentar o papel do enfermeiro e reconhecer o valor do papel que a profissão pode desenvolver dentro de uma equipe interdisciplinar e resolver problemas complexos de saúde. 